DP. 1704

Distribution Category: UC-10

\title{
ADAPTATION OF U(IV) REDUCTANT TO SAVANNAH RIVER PLANT PUREX PROCESSES
}

by

Errol G. Orebaugh

$D P--1704$

DE86 011669

Approved by

H. D. Harmon, Research Manager

Actinide Technology Division

Publication Date: April 1986

E. I. du Pont de Nemours \& Co. Savannah Aiver Laboratory Aiken, SC 29808

PREPARED FOR THE U.S. DEPARTMENT OF ENERGY UNDER CONTRACT DE.ACO9.76SRO0001 


\section{DISCLAIMER}

This report was prepared as an account of work sponsored by an agency of the United States Government. Neither the United States Government nor any agency Thereof, nor any of their employees, makes any warranty, express or implied, or assumes any legal liability or responsibility for the accuracy, completeness, or usefulness of any information, apparatus, product, or process disclosed, or represents that its use would not infringe privately owned rights. Reference herein to any specific commercial product, process, or service by trade name, trademark, manufacturer, or otherwise does not necessarily constitute or imply its endorsement, recommendation, or favoring by the United States Government or any agency thereof. The views and opinions of authors expressed herein do not necessarily state or reflect those of the United States Government or any agency thereof. 


\section{DISCLAIMER}

Portions of this document may be illegible in electronic image products. Images are produced from the best available original document. 


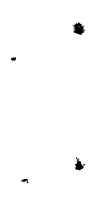


Partitioning of uranium and plutonium in the Purex process requires the reduction of the extracted $\mathrm{Pu}(\mathrm{IV})$ to the less extractable $\mathrm{Pu}(\mathrm{III})$. This valence adjustment at SRP has historically been performed by the addition of ferrous ion, which eventually constitutes a major component of high level waste solids requiring costly permanent disposal. Uranous nitrate, U(IV), is a kinetically fast reductant which may be substituted for $\mathrm{Fe}$ (II) without contributing to waste solids. This report documents U(IV) flowsheet development in the miniature mixer-settler equipment at SRL and provides an insight into the mechanisms responsible for the successful direct substitution of $\mathrm{U}$ (IV) for $\mathrm{Fe}$ (II) in $1 \mathrm{~B}$ bank extractant. U(IV) will be the reductant of choice when its fast reduction kinetics are required in centrifugal-contactor-based processing. The flowsheets investigated here should transfer to such equipment with minimal modifications. 


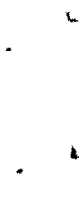

6

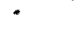




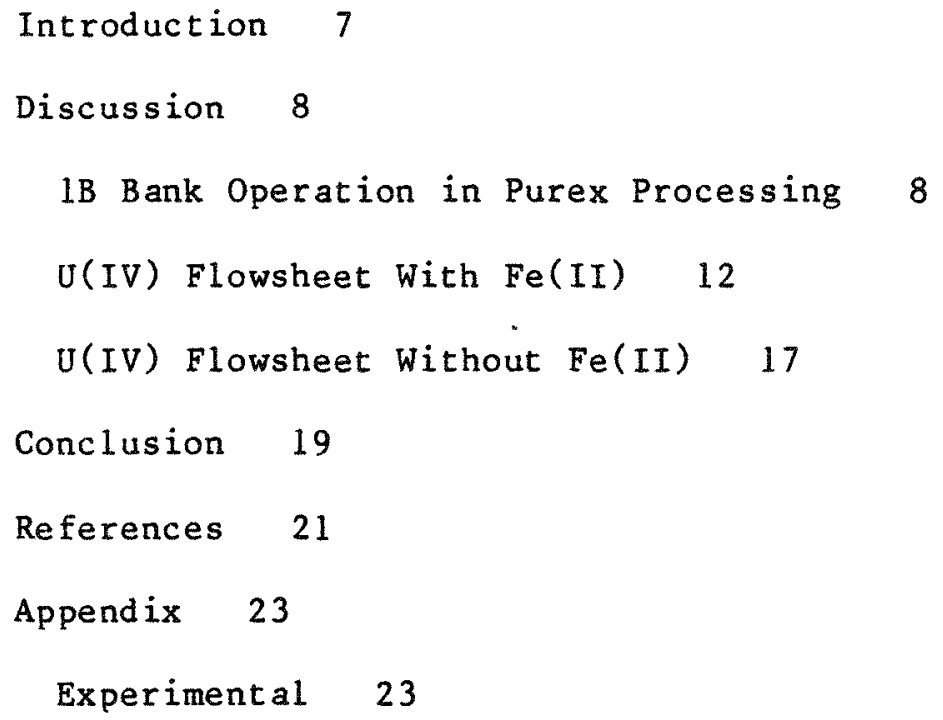




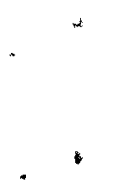




\section{INTRODUCTION}

Uranous nitrate in a hydrazine-stabilized nitric acid media is a powerful reducing agent. It $c$ an be substituted for the usual reductant, ferrous sulfamate (FS), in some Purex processes to decrease the amount of waste generated by the process. SRP has had a continuing interest in such applications since about $1960,1,2$ but these early studies did not provide sufficient cost incentive to continue the work into plant demonstrations. Elsewhere, 3,4,5 waste considerations were more important, and product specifications less stringent, so that the U(IV) reductant could be used to advantage. For example, the Eurochemic Co. (Mol, Belguim) reported ${ }^{6}$ the use of $U($ IV) reagent in its pulse column facility, but its plutonium product stream contained several thousand Ppm uranium which its process could tolerate. Similarly, the Japanese reported ${ }^{7}$ the use of $U(I V)$ reductant with mixersettler equipment, but they obtain a $\mathrm{Pu} / \mathrm{U}$ product ratio of only 0.45 after the second extraction cycle.

Increased interest in reducing both near-term and long-term waste costs led to a resumption of interest in U(IV) reductant at SRP. An efficient electrolytic process ${ }^{8}$ for generating the reagent was developed, and studies were initiated to re-examine the application to existing large-scale plant equipment without compromising product specifications. The greatest incentive by $f a r$ is to replace FS as the plutonium reductant in $1 B$ bank where it was used at $0.14 \mathrm{M}$ in the $1 \mathrm{BX}$ stream. Parallel waste reduction effort, 9,10 in which hydroxylamine nitrate (HAN) was substituted for a major portion of the FS, have proven to be more cost effective at present, due mainly to the capital costs of U(IV) production. The reduction kinetics of $U$ (IV) are fast compared to those of HAN. Although HAN has proven to be satisfactory in mixersettler applications where the residence time in the settlers is sufficient for adequate regeneration of the ferrous ion, any future conversion of bank $1 B$ operations to centrifugal-contactor-based processing will find $U(I V)$ the preferred fast reductant.

This report details the various considerations that are important in substituting U(IV) for FS in the first cycle partitioning flowsheet. This work confirms and extends an earlier study of this system by Schlea et al.1 


\section{DISCUSSION}

\section{IB Bank Operation in Purex Processing}

The purpose of the partitioning or $1 \mathrm{~B}$ bank operation is to chemically reduce plutonium to the less extractable $\mathrm{Pu}$ (III) valence state and to strip it into an aqueous stream leaving uranium in the organic phase. This operation is easier to understand from the entire first cycle operations shown schematically in Figures 1 and 2 .

In the lA bank, plutonium and uranium are introduced in an aqueous acid feed ( $1 \mathrm{AF}$ ) derived from nuclear fuel/target dissolution. While the details of bank A flowsheets vary depending upon the exact source of the fissile materials, the purpose of this bank is to extract plutonium and uranium into a $30 \%$ tributylphosphate (TBP) extractant in n-dodecane type solvent (1AX), leaving the majority of fission products and other impurities in the aqueous waste stream ( $1 \mathrm{AW})$. Since the plutonium $c$ an exist in several valence states, nitrite (IAN) is added to the bank to promote the more extractable $\mathrm{Pu}$ (IV) state and to oxidize neptunium to less extractable forms to ensure its rejection to the $1 \mathrm{AW}$.

When a solvent extraction bank is center fed, the bank $c$ an be logically divided into an extraction and a scrub section. In bank $1 \mathrm{~A}$, the extraction section lies to the right or in the direction of the aqueous feed travel. The extracted uranium and plutonium travel to the left in the organic phase flow direction. In addition to extracting uranium and plutonium, certain fission products ( $\mathrm{Zr}-\mathrm{Nb}, \mathrm{Ru}$, etc.) are weakly extracted. The purpose of the scrub section is to provide an opportunity to strip these fission products back to the aqueous phase, thus increasing the overall decontamination factor for the operation. Increased acid level in the aqueous scrub (IAS) promotes this decontamination. The flow ratios of the various streams must be carefully controlled so as to provide the optimum degree of saturation of the solvent with the fissile materials. If the saturation is below normal, the increased concentration of the free TBP will promote extraction of fission products and acid from the aqueous phase, while overloading of the organic will eventually cause loss of fissile materials to the $1 \mathrm{AW}$.

The operation of $1 B$ bank, while different in detail, is the same schematically. The feed to the bank is the loaded solvent product of $1 \mathrm{~A}$ bank. Like $\mathrm{IA}$ bank, $\mathrm{IB}$ bank is center fed. The extraction section again lies in the direction of the feed flow but now it is to the left. As previously noted, the plutonium is chemically reduced and extracted to the aqueous phase. This chemical reduction is traditionally done with ferrous ion. Since the system also requires an antioxidant, usually sulfamate, 


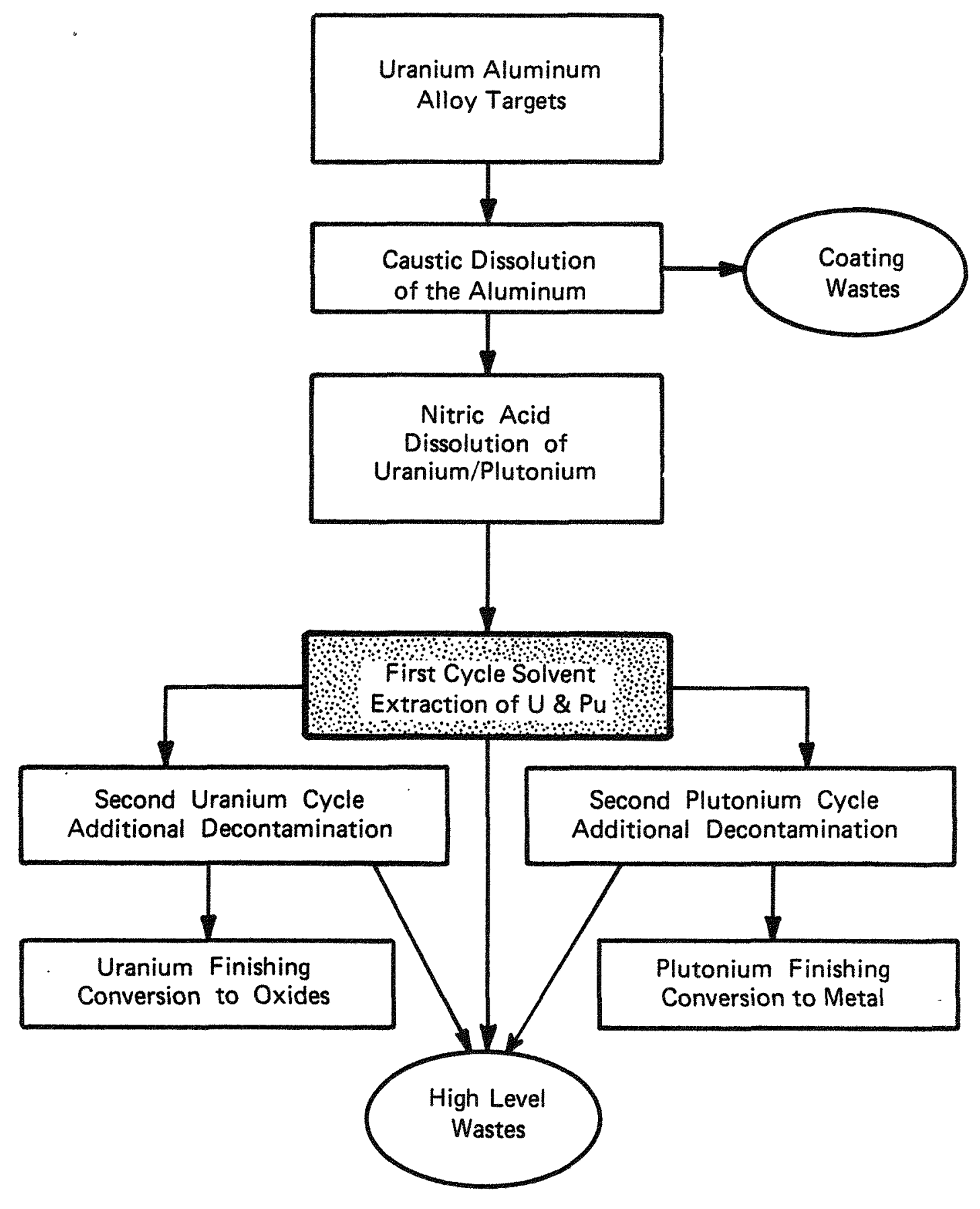

FIGURE 1. F-Area Target Processing 


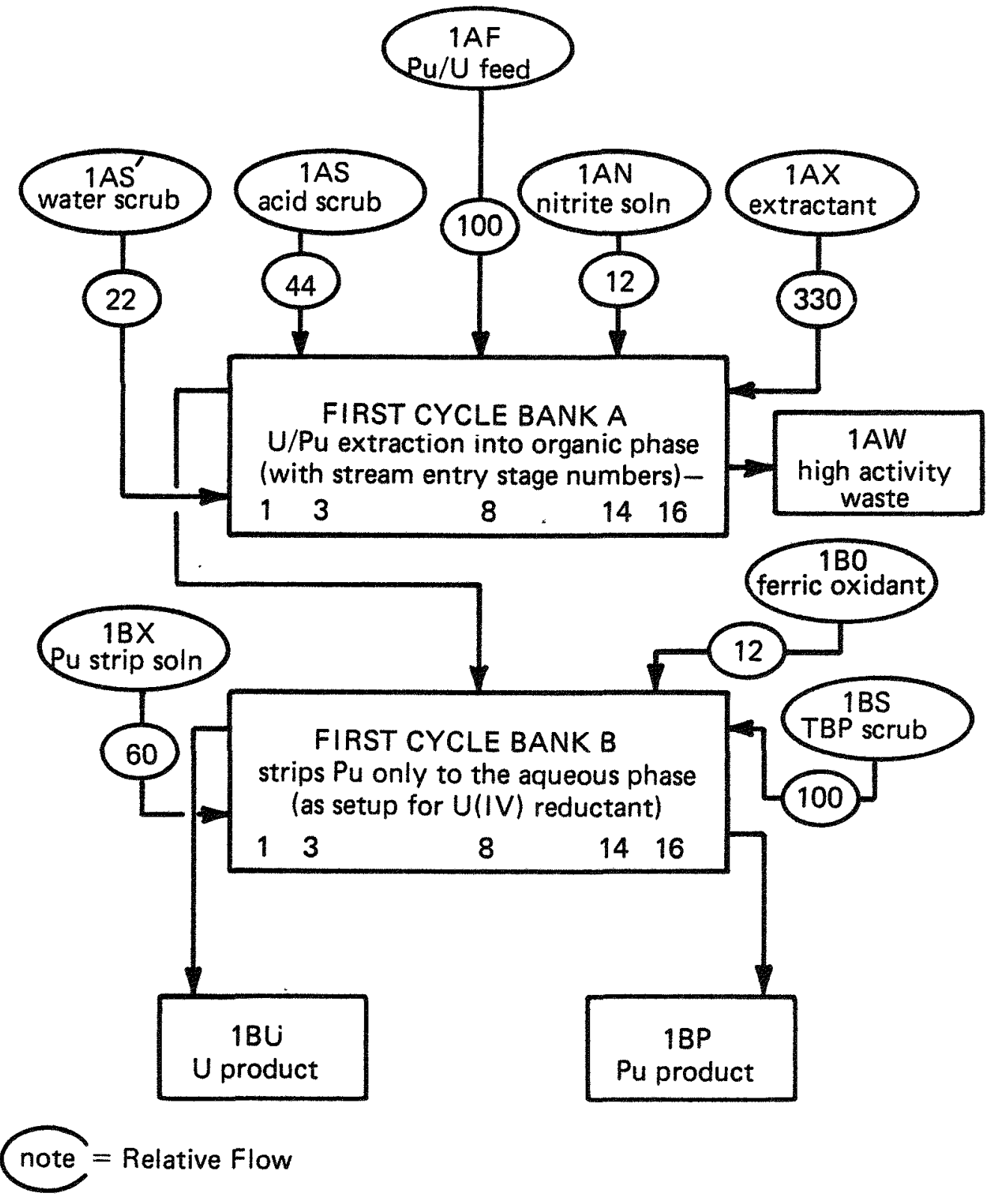

FIGURE 2. Banks $A$ and $B U$ (IV)/Hydrazine Flowsheet 
ferrous sulfamate (FS) has been the reductant of choice. The ferrous ion introduced in the $1 \mathrm{BX}$ does not extract into the solvent, therefore the chemical reduction must take place in the aqueous phase. Since the $\mathrm{Pu}$ (IV) distribution allows only a small concentration of $\mathrm{Pu}(\mathrm{IV})$ to exist in the aqueous phase, the reduction reaction must be kinetically fast to promote the required mass transport of plutonium to the aqueous phase.

Unfortunately, the $\mathrm{Pu}($ III) does not remain entirely in the aqueous phase but redistributes to the organic phase as the $\mathrm{Pu}\left(\mathrm{NO}_{3}\right)_{3}$ (TBP) $\mathrm{n}$ species. Although the distribution coefficient for Pu(III) is small, the relative organic to aqueous flow ratio is 1 arge and the combination requires about six extraction stages to reduce the plutonium loss to the organic stream (1BU) to less than $0.01 \%$. This means that the chemical reduction must be complete within two stages when feed is fed to the bank at stage 8 . Since the reduction kinetics are highly acid dependent, high acid levels at the reductions stages can result in less efficient reduction, thus increasing the number of extraction stages required.

The function of the scrub section is simply to re-extract the uranium that distributed to the aqueous phase at the feed point. This is accomplished by bringing in fresh solvent as the 1BS scrub. With the eight stages available and the favorable flow ratios and distribution ratios for $U(V I)$, the uranium contamination of the plutonium product ( $1 B P$ ) is reduced to sub-PPB levels in laboratory scale studies. However, at this end of the bank, the plutonium concentration is high in the aqueous phase and the distribution coefficient of $\mathrm{Pu}$ (III) leads to about $3 \%$ of the plutonium existing in the organic phase. This organic plutonium causes considerable radiolysis of the nitrate in the TBP solvent phase. The result is the formation of an oxidizing condition in the solvent.

The sulfamate component of the FS has the function of destroying these oxidants when they are stripped to the aqueous phase throughout $1 B$ bank. Since sulfamate or any other such reagent is not extractable by the solvent, it cannot affect the oxidizing condition in the bulk solvent itself.

This oxidizing organic phase complicates the function of the scrub section. The $3 \%$ of the aqueous $\mathrm{Pu}$ (III) that distributes to the solvent becomes oxidized and must be reduced again at the next contact with the aqueous reductant. Fortunately, the sulfamate anti-oxidant is always present at each mixing operation and neutralizes the oxidizing potential of the solvent in the emulsion. If the solvent remained oxidizing in the emulsion, prompt $\mathrm{Pu}$ (III) oxidation would allow much more plutonium to transfer to the organic phase at each contact. The result of insufficient reductant or reduction kinetics at each stage in the scrub section would be plutoniom reflux within the bank. 
Plutonium reflux $c$ an be defined as any accumulation of plutonium in the system due to recycle. Operationally, the concern is with significant accumulations which would present nuclear criticailt; problems. The lack of reductant in the final scrub stages would allow Pu(IV) to accumulate in the organic phase until a lower stage was reached in which reductant was present to reductively strip the plutonium to the aqueous phase, leaving only that plutonium needed to satisfy the $\mathrm{Pu}$ (III) distribution equilibrium. If only 3 or 4 stages are not reductive toward $P u(I V)$, significant accumulations are not observed. However, if the antioxidant is exhausted before exiting in the 1BP, the amount of plutonium recycled per stage $c$ an increase greatly and serious reflux can occur rapidly.

The function of $1 \mathrm{~B}$ bank $\mathrm{c}$ an be summarized as follows:

- Remove $>99.99 \%$ of the plutonium from the uranium product.

- Attain less than $100 \mathrm{ppm}$ uranium contamination of the plutonium.

- Maintain conditions which are consistant with nuclear safety.

\section{U(IV) Flowsheet With $\mathrm{Fe}($ II)}

Unlike the ferrous ion, U(IV) behaves much like $\mathrm{Pu}(\mathrm{IV})$ and is fairly extractable by the solvent. Therefore, our early studies introduced $U$ (IV) as a separate stream near the center of $1 B$ bank near the feed stage. This was based on the belief that the U(IV) would distribute to the scrub section via aqueous phase transport and provide reductive conditions to reverse interstage oxidation of plutonium. Since no U(IV) is allowed to exit the scrub section in the 1BP, the net $f l u x$ of $U(I V)$ into the scrub section must only compensate for that actually oxidized. Most of the U(IV) would be extracted by the solvent and carried through the extraction section to exit in the 1BU. The aqueous phase concentrations of U(IV) in the extraction section are in dynamic equilibrium with the main flux of $U(I V)$ in the organic. Therefore, the U(IV) consumed in the primary reduction of plutonium is replaced by a net loss in the organic phase. This arrangement was felt to provide versatility by allowing the reductant entry point to be shifted either way to optimize conditions. Short duration tests with this flowsheet configuration offered hope for success but were inconclusive.

Parallel studies by M. C. Thompson at SRL used a combiration of FS and U(IV) with some success. When this approach was tried, the addition of low concentrations of FS or ferrous nitrate/ hydrazine tn the 1BX, combined with a reduction in the stoichiometric excess of U(IV) resulted in apparently improved decontamination of both the IrU and IBP product streams. The improvement made sense because the ferrous ion was much faster kinetically in the reduction of $\mathrm{Pu}(\mathrm{IV})$ during the mixing operation and provided total $\mathrm{Pu}$ reduction in fewer contactings, while the presence of U(IV) in 
the aqueous phase would restore a very strong ferrous reduction potential during the residence time in the settler. The decreased plutonium reflux tendency was the result of the ferrous reductant maintaining reducing curditions beyond the point of U(IV) exhaustion in the scrub section.

Tests under such conditions looked encouraging but the $U$ (IV) refluxed in the bank. With time, the U(IV) built up to levels such that the scrub section was not effective in its removal and excessive contamination of the $1 B P$ product stream occurred. The problem was traced to the acid profile within 1B bank. Figure 3 presents a fairly typical acid profile of the bank resulting from a normal lA bank configuration providing the majority of the acid feed to $1 \mathrm{~B}$ bank. Since the uranium in both the aqueous and organic phases is roughly constant throughout the extraction section, the acid profile is the main factor that controls the U(IV) distribution. As the acid profile drops toward $1 \mathrm{BU}$ exit stage, stage 1 , it forces the U(IV) distribution coefficient to drop also. In moving against a decreasing acid profile, the organic must transfer a portion of its U(IV) content to the aqueous phase causing its reflux.

Because of this reflux, any excess $U(I V)$ reductant will eventually build to levels that will cause $U$ contamination of the 1BP. The amount of U(IV) at a given point in the banks must be continuously monitored and the addition rate of the reductant adjusted to stabilize the reflux at a permissible level.

Since it is impossible to operate our present large scale mixer/settler equipment in such a demand mode, the flowsheet must be made to work in an excess mode. Initially, introduction of $U$ (IV) via the $1 \mathrm{BX}$ was believed to be useless since its concentration would be reduced by extraction too rapidly. However, with the use of ferrous sulfamate as a co-reductant, it would only be necessary for sufficient $U($ IV) to reach the feed stage to restore the ferrous reduction potential and allow ferrous ions to furnish reducing conditions throughout the scrub section. When this approach was tested, U(IV) surprisingly moved right to the center feed stage without significant reduction in concentration. While this was unexpected, the reason is apparent in the acid profile.

When introduced in the $1 \mathrm{BX}, \mathrm{U}(\mathrm{IV})$ must flow to the center of the bank against an increasing acid profile and a constant uranyl media. Beyond the center feed point, the extraction coefficient increases rapidly due to the increased free TBP concentration. This reduces the amount of J(IV) inventory required to achieve steady state conditions in the scrub section. In the extraction section, a steady-state condition is rapidly achieved in which the only net flux of U(IV) toward the center feed point is that required to compensate for the oxidation of the reductant. In 
Bank 1B
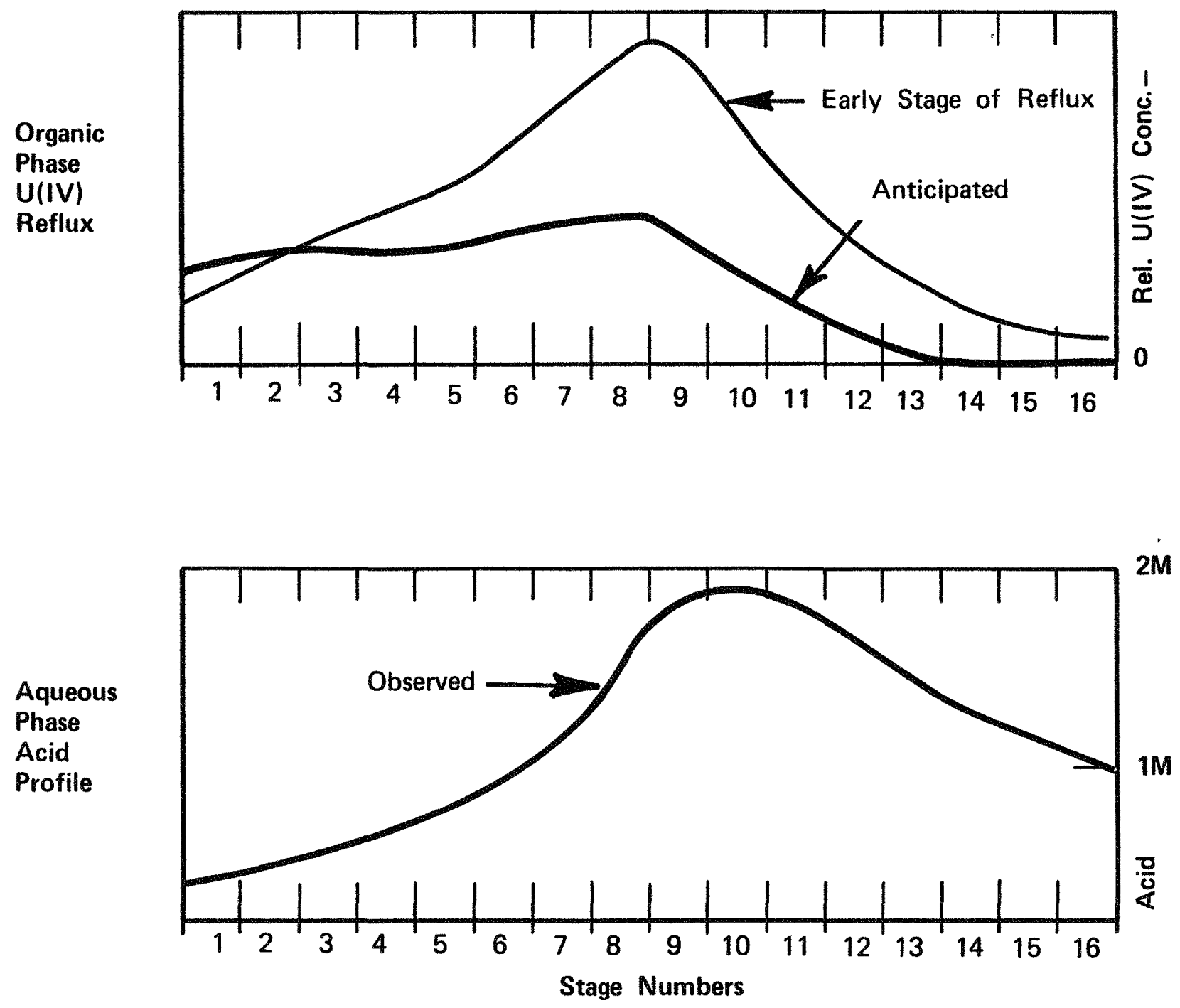

FIGURE 3. Approximate U(IV) Profiles for Center-Fed U(IV) Reductant 
progressing toward the center, each stage has a lower U(IV) aqueous equilibrium concentrations than the previous one. This results in a U(IV) profile similar to that shown in Figure 4. Note that if the acid profile can be kept fairly flat in the extraction sectior. there will be a minimal decrease in U(IV) concentration from stage 1 to stage 8. The addition of ferric nitrate solution (1BU) at stage 14 was tested as a U(IV) oxidant to ensure minimal contamination of the $1 B P$ product by uranium. The necessity for this small additional source of iron was not demonstrated experimentally, but it should be included in all U(IV) flowsheets to ensure 1BP quality.

This U(IV)/Fe/hydrazine flowsheet was highly successful and comparable in preformance with the existing SRP flowsheet. It was tested successfully at $0.01 \mathrm{M}$ Fe and $0.015 \mathrm{M}$ U(IV) as shown in Table 1. The flowsheet was conservatively specified at $0.02 \mathrm{M} \mathrm{Fe}$ for the plant to ensure that there would be no plutonium reflux. The U(IV) concentration was also believed to be conservative and could likely be reduced following actual experience in full-scale equipment. This represented a $75 \%$ reduction of iron in the waste resulting from bank $1 \mathrm{~B}$ reductant compared to the $0.08 \mathrm{M}$ FS/0.06M HAN flowsheet then in use at SRP. At about the same time as this U(IV) work, a modified FS/HAN flowsheet that reduced the FS requirement to $0.04 \mathrm{M}$ was developed and tested successfully in the plant. This change required the complete elimination of iron in the $I B X$ in order for U(IV) to remain a viable alternative reductant.

TABLE 1

U(IV)/Ferrous/Bydrazine Flowsheet

\begin{tabular}{|c|c|c|c|}
\hline Stream & $\begin{array}{l}\text { Entry } \\
\text { Stage } \\
\end{array}$ & $\begin{array}{l}\text { Rel } \\
\text { Flow } \\
\end{array}$ & Composition \\
\hline IAF & $9 A$ & 100 & $<1 \mathrm{~g} / \mathrm{L} \mathrm{Pu}, 300 \mathrm{~g} / \mathrm{L} \mathrm{U}, 1 \mathrm{M} \mathrm{HNO}_{3}$ \\
\hline IAN & $14 \mathrm{~A}$ & 12 & $0.35 \mathrm{M}$ sodium nitrite \\
\hline IAS & $1 \mathrm{~A}$ & 66 & 3.OM nitric acid \\
\hline IAX & $16 \mathrm{~A}$ & 330 & $30 \%$ tributylphosphate in $\mathrm{N}$-dodecane \\
\hline IBS & $16 B$ & 100 & $30 \%$ tributylphosphate in $\mathrm{N}$-dodecane \\
\hline $1 B O$ & $14 \mathrm{~B}$ & 12 & $0.005 \mathrm{M}$ ferric nitrate solution \\
\hline $1 \mathrm{BX}$ & $1 B$ & 60 & $\begin{array}{l}0.015 \mathrm{M} U \text { (IV) in variable uranyl nitrate } \\
0.020 \mathrm{M} \text { ferrous nitrate } \\
0.10 \mathrm{M} \text { hydrazine nitrate } \\
0.2 \mathrm{M} \text { nitric acid }\end{array}$ \\
\hline
\end{tabular}



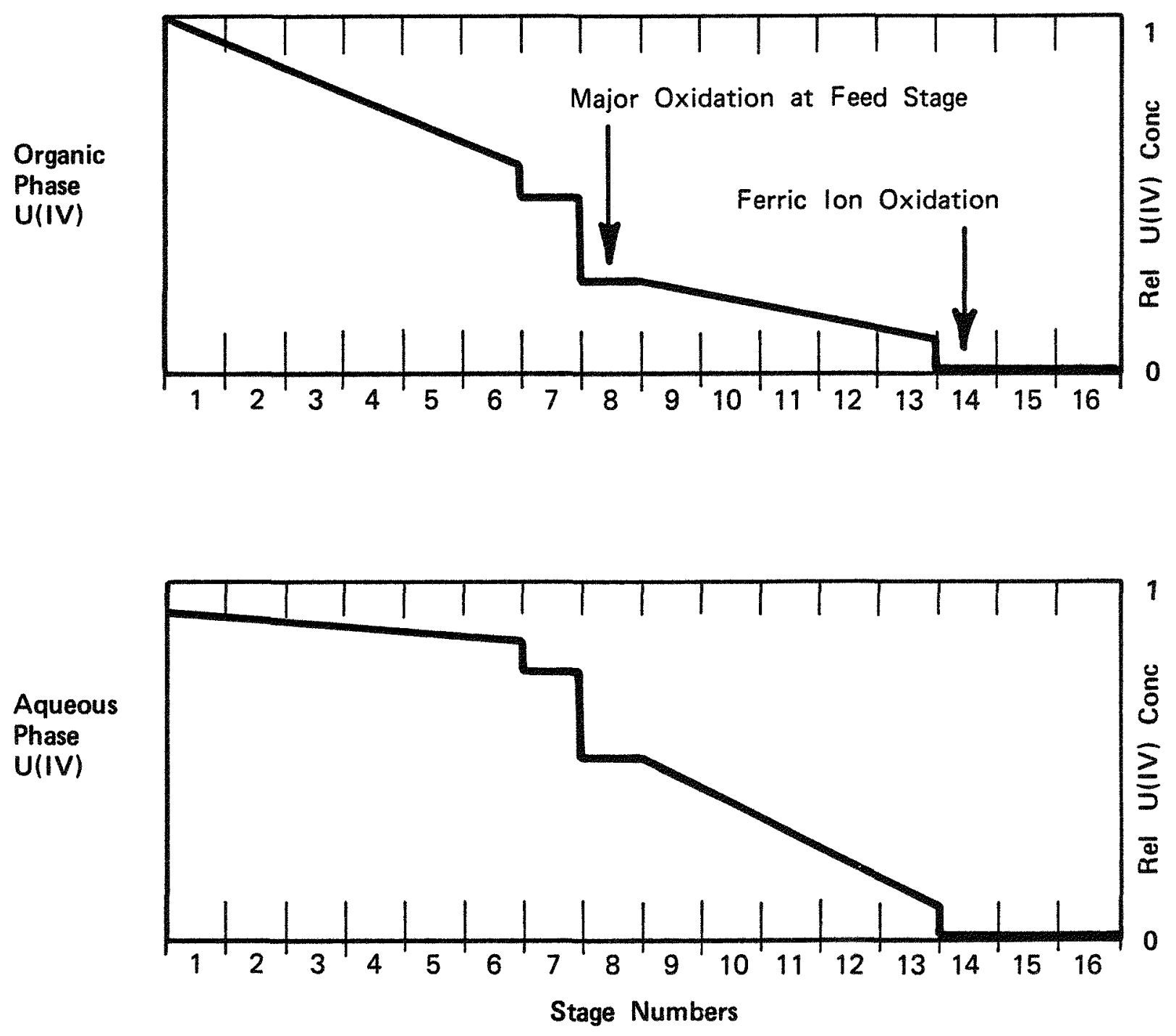

FIGURE 4. IB Bank Profiles 


\section{U(IV) Flowsheet Without $\mathrm{Fe}(\mathrm{II})$}

The original test of the flowsheet given in Table 2 was with a nomal $1 \mathrm{~A}$ bank configuration and with $1 \mathrm{~B}$ bank operated at $35^{\circ} \mathrm{C}$. Under these conditions, 1B bank acid profile increases rapidly through the extraction section as shown in Figure 5. The data from this test showed undesirable plutonium losses (approaching $0.1 \%$ ) to the 1BU. The plutonium reflux, however, appeared to be limited to a stage-by-stage accumulation of reoxidized plutonium in the organic phase that should not present serious problems. The lack of adequate plutonium stripping from the organic phase was attributed to a higher acid concentration in this test compared to that in prior work. Though the higher acidity resulted from an experimental error, this test showed that $\mathrm{Pu}(\mathrm{IV})$ reduction kinetics by U(IV) would be significantly modified by such acid variation. To reduce the acid levels in $1 B$ bank and provide faster kinetics,11,12 the same strategy as is currently employed in the modified FS/HAN flowsheet was adopted: add a separate final water scrub to $1 \mathrm{~A}$ bank to strip excess acid from the lAP. When this was done, the acid profile was strongly supressed as illustrated by the bottom curve in Figure 5. This resulted in the plutonium losses decreasing below $0.01 \%$.

\section{TABLE 2}

U(IV) Hydrazine Flowsheet

\begin{tabular}{|c|c|c|c|}
\hline Ste am & $\begin{array}{l}\text { Entry } \\
\text { Stage }\end{array}$ & $\begin{array}{l}\text { Rel } \\
\text { Flow }\end{array}$ & Composition \\
\hline $1 \mathrm{AF}$ & $9 \mathrm{~A}$ & 100 & $<1 \mathrm{~g} / \mathrm{L} \mathrm{Pu}, 300 \mathrm{~g} / \mathrm{L} \mathrm{U}, 1 \mathrm{M} \mathrm{HNO}$ \\
\hline IAN & $14 \mathrm{~A}$ & 12 & $0.35 \mathrm{M}$ sodium nitrite solution \\
\hline IAS & $3 \mathrm{~A}$ & 44 & 4.5M nitric acid \\
\hline $1 \mathrm{AS}^{-}$ & $1 \mathrm{~A}$ & 22 & acidified water \\
\hline IAX & $16 \mathrm{~A}$ & 330 & $30 \%$ tributylphosphate in $\mathrm{N}$-dodecane \\
\hline IBS & $16 B$ & 100 & $30 \%$ tributylphosphate in $\mathrm{N}$-dodecane \\
\hline $1 \mathrm{BO}$ & $14 B$ & 12 & $0.005 \mathrm{M}$ ferric nitrate solution \\
\hline $1 \mathrm{BX}$ & $1 B$ & 60 & $\begin{array}{l}0.015 \mathrm{M} \mathrm{U}(\mathrm{IV}) \text { in variable urnayl nitrate } \\
0.10 \mathrm{M} \text { hydrazine nitrate } \\
0.20 \mathrm{M} \text { nitric acid }\end{array}$ \\
\hline
\end{tabular}




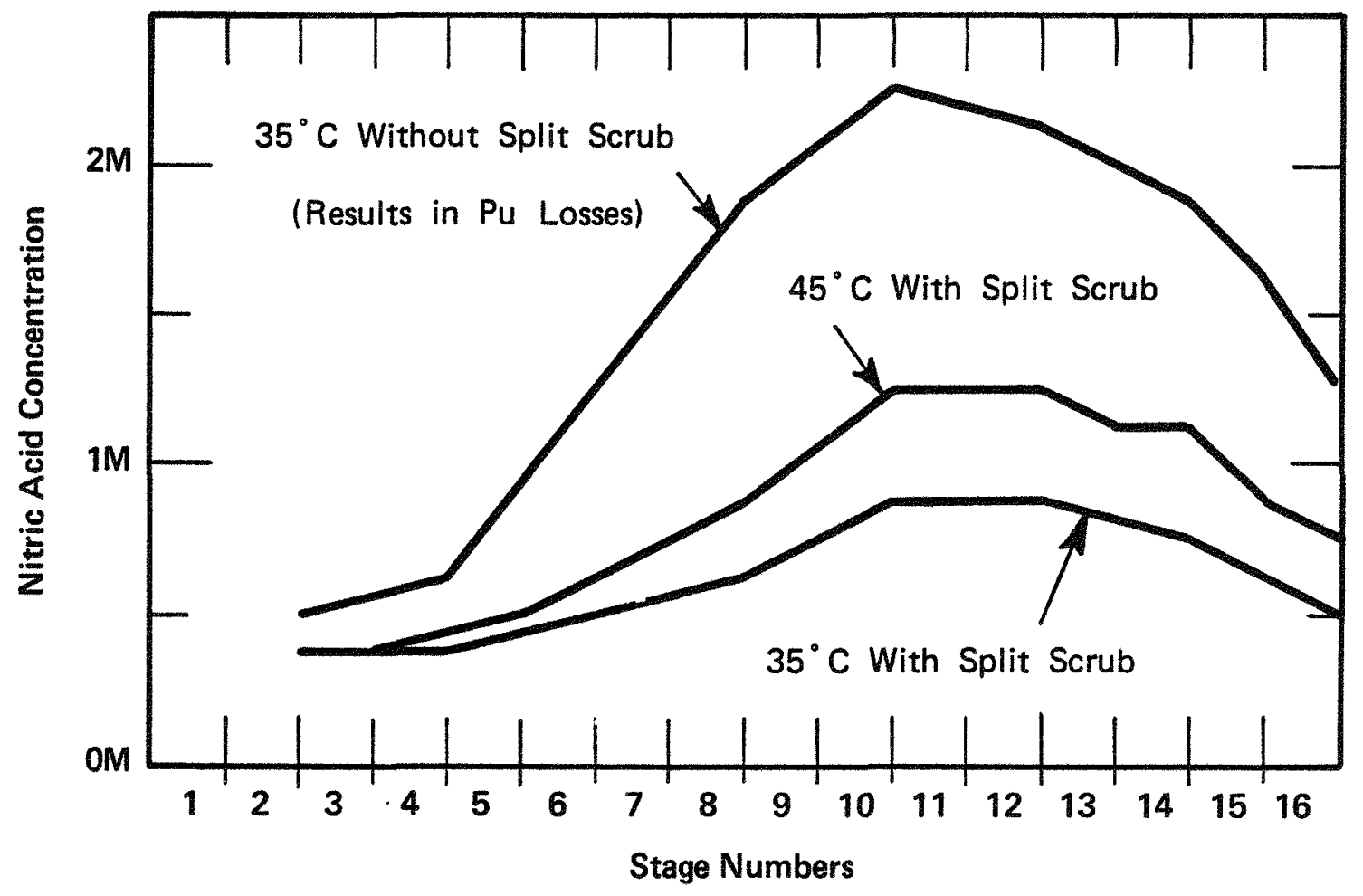

FIGURE 5. Experimental 1B Bank Acid Profile - Acid Reduction via Split Scrub Permitted Acceptable Pu Losses 
The final testing of the flowsheet was to demonstrate its behavior at $45^{\circ} \mathrm{C}$ where plant operation is prefered. By increasing the operating temperature to $45^{\circ} \mathrm{C}$, the $1 B S$ scrub extracts a little more acid from the exiting $1 \mathrm{BP}$ stream. The acid reflux increases slightly within $1 B$ bank, but not enough to be detrimental to good operating behavior.

The uranium and plutonium profiles across $1 \mathrm{~B}$ bank for the flowsheet are shown in Figure 6. The accuracy of the data is confirmed by the distribution coefficients that $c$ an be calculated from it. From the aqueous uranium concentration in the scrub section, the $D_{U}$ is found to be 8.9 vs. 1iteraturel3 values of 8.6 extrapolated for the existing conditions. Correspondingly, the $\mathrm{Pu}$ (III) distribution in the extraction section from both the aqueous and organic curves is 0.04 which compares well with literature values at these acidities and uranium concentrations.

The rise in plutonium concentrations in the organic phase from stage 16 to stage $12 \mathrm{can}$ be accurately predicted if the amount of $\mathrm{Pu}($ III) which distributes to the organic phase at each mixing stage is calculated using the appropriate $D_{\mathrm{Pu}}(\mathrm{III})$ for the local acidity and assuming that oxidation to Pu(IV) occurs without interstage reduction until stage 12 .

The plutonium profiles show a mincr steady-state plutonium reflux with this iron-free flowsheet, but it is insignificant from a criticality safety view. Though the actual concentration of uranium in the $1 \mathrm{BP}$ is well below the analytical detection limit, the theory of solvent extraction combined with the linearity of the uranium curve through the scrub section suggest that the extrapolated $2 \mathrm{ppb}$ concentration of uranium at stage 16 is a valid estimate and easily meets SRP specifications. Similarly, the plutonium analysis for the IBU combined with the appropriate flow ratios show that the losses are acceptable.

\section{CONCLUSION}

The partitioning of uranium and plutonium in 18 bank is a straight-forward application of chemistry and chemical engineering. Although the simultaneous operations of valence state adjustment and solvent extraction occur, this study has shown that the valence adjustment is fast using $U(I V)$. Therefore computer modeling of such systems $c$ an be simplified by the elimination of kinetic terms when dealing with mixer-settler units. 


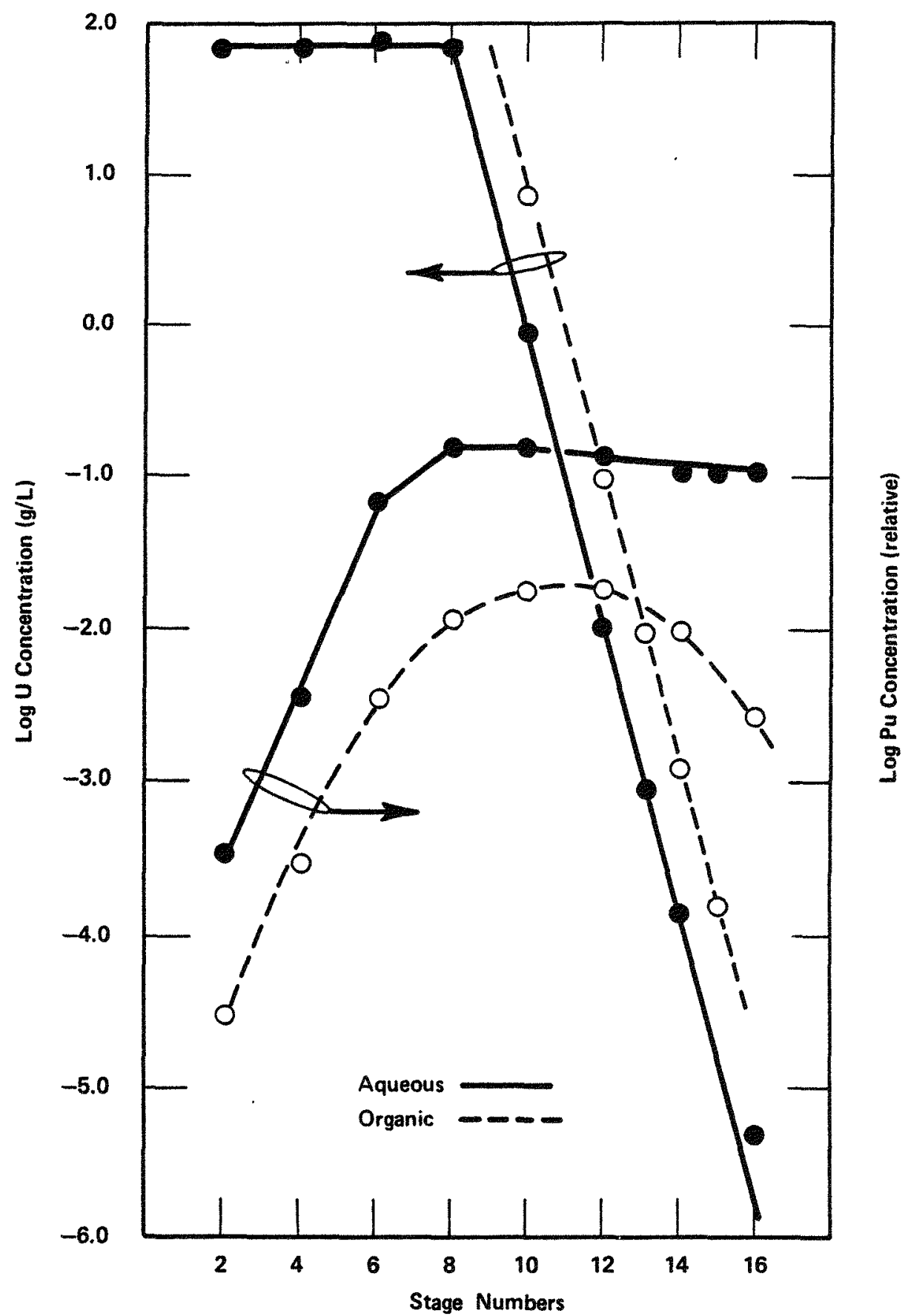

FIGURE 6. Extraction Profiles for $U$ and $P u$ in Bank $1 B$ as Observed Using the U(IV) Flowsheet 
Loss of reductant or anti-oxidant has quite different consequences for partitioning. Loss of reductant in the final scrub stages allows a predictable increase in the organic plutonium content. This condition can be easily tolerated as it is a steadystate condition. However, loss of anti-oxidant in these same stages will result in unpredictable large-scale oxidation of $\mathrm{Pu}($ III) in the aqueous phase, leading to unsafe plutonium reflux conditions.

Unlike the current modified FS/HAN flowsheet, the U(IV) flowsheet does not depend upon kinetically slow reactions to restore reductive power during residence time in the settler. Therefore, if centrifugal contactors are substituted for mixersettlers in bank 1B, the U(IV) flowsheet would be expected to apply to the new equipment with little modification.

\section{REFERENCES}

1. C. S. Schlea, M. R. Caverly, H. E. Henry, and W. J. Jenkins. Uranium(IV) Nitrate as a Reducing Agent for Plutonium(IV) in the Purex Process. USAEC Report DP-808, E. I. du Pont de Nemours \& Co., Savannah River Laboratory, Aiken, SC (1963).

2. G. S. Nichols, Electrolytic Preparation of Uranous Nitrate. USDOE Report DP-1065, E. I. du Pont de Nemours \& Co., Savannah River Laboratory, Aiken, SC (1966).

3. R. J. W. Streeton and E. N. Jenkins. The Preparation, Stabilization, and Analysis of U(IV) Nitrate Solutions. AERE-R-3938 (1962).

4. E. Lodez-Menchero, L. Salomon, and G. Bardone. Study of Uranium (IV) as Reducing Agent for Plutonium, IIa - Stability of Uranium (IV) in Solution. Eurochemic Technical Report No. 181, NP-16328 (March 1966) and ETR 186 (1967).

5. X. L. R. Talmont. Utilization of Uranium (IV) Nitrate in a Second Cycle of Purification of Plutonium by TBR. Proceedings International Solvent Extraction Conference (1965).

6. J. van Geel, C. Joseph, E. Detilleux, W. Heinz, J. Centeno, and B. Gustafsson. Chemical Aspects of Solvent Extraction on Plant Scale at Eurochemici, Proceedings International Solvent Extraction Conference (1971).

7. T. Segawa, T. Hoshino, A. Kaya, K. Gonda, T. Tsuboya, and C. Tanak. Flowsheet Studies on Reprocessing of Japan Experimental Test Reactor Fuel in a PUREX Plant. Proceedings International Solvent Extraction Conference (1971). 
8. E. G. Orebaugh and R. C. Propst. Electrolytic Production of Uranous Nitrate. USDOE Report DP-1549, E. I. di Pont de Nemours \& Co., Savannah River Laboratory, Aiken, SC (1980).

9. J. Malvyn McKibben and J. E. Bercaw. Hydroxylamine Nitrate as a Plutonium Reductant in the Purex Solvent Extraction Process. USDOE Report DP-1248, E. I. du Pont de Nemours \& Co., Savannah River Plant, Aiken, SC (1971).

10. J. Malvyn McKibben, D. F. Chostner, and E. G. Orebaugh. Plutonium-Uranium Separation in the Purex Process Using Mixtures of Hydroxylamine Nitrate-Ferrous Sulfamate. USDOE Report DP-1656, E. I. du Pont de Nemours \& Co., Savannah River Plant, Aiken, SC (1983).

11. T. W. Newton. The Rinetics of the Reaction Between $\mathrm{Pu}(\mathrm{IV})$ and $\mathrm{U}(\mathrm{IV})$. J. Phys. Chem. 63, 1493 (1959).

12. V. I. Marchenko and V. S. Koltunov. Kinetics of the Reaction of Plutonium Ions with Tetravalent Uranium in Nitric Acid. I. Reduction of $\mathrm{Pu}(\mathrm{IV})$. Sov. Radiochem. 16, 477 (1974).

13. S. V. Bagawde, P. R. Vasadeva Rao, V. V. Ramakrishna, and S. K. Patil, Effect of Temperature on the Extraction of Oranium(VI) From Nitric Acid by Tri-n-Butyl Phosphate, Government of India Atomic Energy Commission Report BAkC-952, Bhadha Atomic Research Center, Bombay, India (1978).

14. C. S. Schlea, M. R. Caverly, E. C. Horni, H. E. Henry, and W. J. Jenkins. A Miniature Pilot Plant for Processing Irradiated Nuclear Fuel. USAEC Report DP-757, E. I. du Pont de Nemours \& Co., Savannah River Laboratory, Aiken, SC (1962). 


\section{EXPERIMENTAL}

\section{Equipment}

Solvent extraction processes at SRP have been based upon mixer-settler units of various sizes depending upon the particular cycle and criticality considerations. Centrifugal contactors were developed in the $1960^{\prime}$ 's and were introduced to the Purex process in first cycle $1 \mathrm{~A}$ bank where they offered the greatest advantage in reducing radiation damage to the solvent due to the reduced residence time inherent in the design. Since this equipment has proven reliable, we can expect future equipment to incorporate this design. However, existing mixer-settler-type equipment will dictate flowsheet design for the present. The testing of $1 \mathrm{~B}$ bank flowsheets for mixer-settlers is largely independent of the equipment used in $1 \mathrm{~A}$ bank. For this reason, the flowsheet studies described in this report were done exclusively with miniature mixer-settler equipment originally described by Schlea, et al.14

Each bank o: miniature mixer-settler equipment consists of 16 stages in which countercurrent aqueous and organic phases are contacted as an emulsion and then allowed to separate by gravity. A schematic of this equipment is shown in Figure 7 . For $1 \mathrm{~B}$ bank flowsheet studies two units are used in cascade, $1 \mathrm{~A}$ bank continuously producing feed for $1 \mathrm{~B}$ bank. 1C bank is not required for studies limited to $1 \mathrm{~B}$ bank performance. The flowrates of the various input streams are established by positive displacement pumps made by Fluid Metering Co. The existing streams are transfered by aspiration to collection tanks with or without passing through in-line instrumentation.

The in-line instrumentation available at this time consists of solid-state silicon alpha detectors which view the radioactive solution through a $0.25 \mathrm{mil} \times 1$ inch window at a distance of about 0.2 inch. With this geometry, the detected count rate is about $0.1 \%$ of the disintegration rate per $\mathrm{mL}$. The alpha detector may be used on either aqueous or organic streams. The remote sensing cell of a Mettler-Paar "Densitymeter" may be used alone or in series with the alpha detecior. With the input stream properly temperature conditioned to $0.01^{\circ} \mathrm{C}$, the density meter provides data accurate to the $4 \mathrm{th}$ decimal place and is highly stable over long periods. 


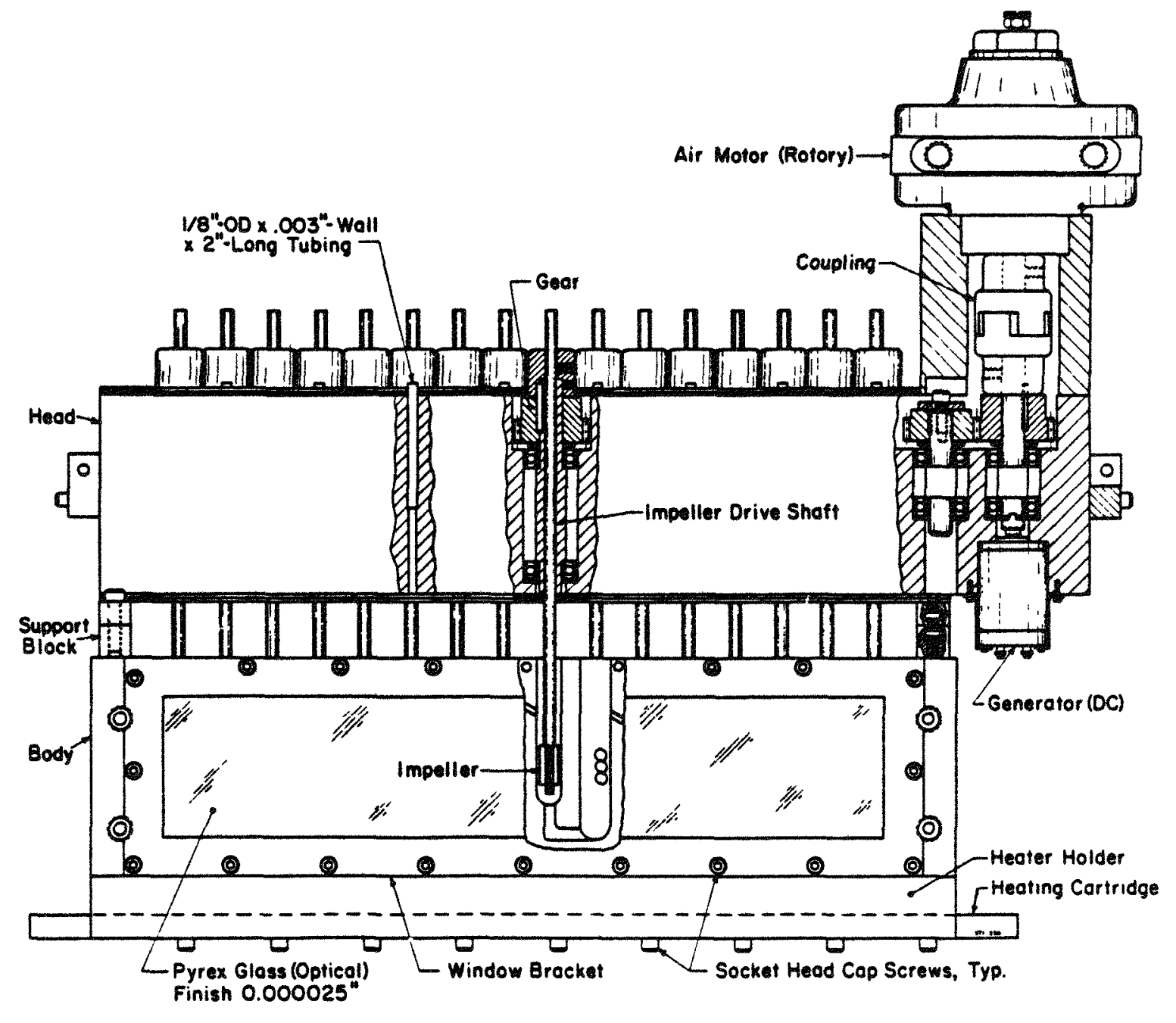

Figure 7. Miniature Mixer-Settler Apparatus used in this Study. (Original Design of Schlea et al.5) 
As mentioned earlier, the exit streams are aspirated from the exit. weirs of the banks to the in-line instrumentation which is located in a neighboring glove box. Transfer by aspiration reduces the delay time that could accumulate by displacement pumping through many feet of tubing, but it also requires consolidation to a bubble-free input to the in-line instrumentation. The deaeration occurs in a small catch pot from which a positive displacement pump delivers a continuous stream to the in-line equipment. The liquid level in the catch pot is controlled by a thermistor probe which actuates the pump motor through an intermediate circuit.

The in-line instrumentation is monitored by a Commodore PET (Commodore Business Machines, Inc.) computer system that has been programed in-house as a data logger and trend display unit. Typically, the unit is set to make a 2-minute alpha count every 4 minutes. During the alpha count the density meter is read every 3 seconds and the average density reading is used to correlate with the average alpha count rate over the same period. The video display allows the most recent 30 data points to be displayed, which in the typical mode corresponds to the past 2 hours of operation. Periodically, the density and alpha data are printed (in graphical form) vs. the time the data period ended. Thus, the most recent trend $c$ an be viewed immediately and earlier data $c a n$ be viewed through the hard copy.

The in-line data have proven invaluable in ensuring the proper behavior of the mixer-settler units. The mixer-settler system is subject to hydraulic surging, but the in-line instrumentation provides graphic evidence of the instabilities, allowing the more serious instabilities to be readily corrected.

\section{Sample Collection}

The major end-streams of concern to the particular flowsheet under study are sampled periodically throughout the test. The resulting data provide evidence for the stability of the flowsheet. At the conclusion of a test, the mixer-settler units and all input streams are stopped and sample aliquots are taken directly from the individual settler stages. This permits the stage-by-stage extraction behavior to be defined and provides concentration profiles of individual species across the bank. 


\section{Analys is}

Table 3 lists the analyses typically preformed for this flowsheet study by the Analytical Development Division at SRL.

TABLE 3

Analyses Typically Preformed for this Flowsheet Study

\begin{tabular}{|c|c|c|}
\hline Species & Method & Range, Media, Accuracy, etc. \\
\hline$U(I V)$ & $\mathrm{Ce}(4)$ titration & $\begin{array}{l}\text { Applied to stock solution and IBX } \\
\text { solution only }\end{array}$ \\
\hline Hydrazine & $\begin{array}{l}\text { Iodate titration } \\
(9 \mathrm{M} \mathrm{HCl})\end{array}$ & $\begin{array}{l}\text { Applied to stock solution and IBX } \\
\text { normally }\end{array}$ \\
\hline$U(V I)$ & $\begin{array}{l}\text { Davies-Grey } \\
\text { titration } \\
\text { Fluorimetric }\end{array}$ & $\begin{array}{l}\text { Applied to organic and aqueous } \\
\text { solution, }>1 \mathrm{~g} / \mathrm{L} \text { after TTA extraction } \\
\text { to exclude } \mathrm{Pu}\end{array}$ \\
\hline $\mathrm{Pu}$ & $\begin{array}{l}\text { Alpha count } \\
\text { Gross alpha }\end{array}$ & $\begin{array}{l}\text { of a TTA extract to eliminate U } \\
\text { interferance when large dilution is } \\
\text { possible }\end{array}$ \\
\hline Acid & Compleximetric & $\begin{array}{l}\text { Titration in } \mathrm{KF} \text { media to a } \mathrm{pH} 7 \\
\text { endpoint, organic phase low in acid } \\
\text { may assay acid deficient }\end{array}$ \\
\hline
\end{tabular}

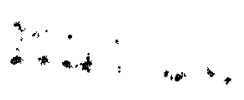

